\title{
EXPERIENCIA ORIGINARIA Y FUNDAMENTACIÓN
}

\author{
Francesc Pereña \\ Universidade de Barcelona
}

Cuando se me pidió un título para mi contribución, mi reacción fue dar el de un tema de grandes vuelos, más que el de uno susceptible de ser abordado razonablemente como objeto puntual y precisamente circunscrito de una breve exposición. Un tema, además, respecto del cual mi posición es la del nadador en un mar de dudas siempre a punto de ahogarse. Pensé primero: ya concretarás más adelante. Pero lo que más adelante pensé fue que difícilmente podría encontrar un marco y una compañía mejores que los presentes para poner las dudas y algunos aspectos del tema sobre la mesa. Así que esto es lo que voy a hacer.

En efecto aún suponiendo (lo que ya de por sí es mucho suponer) que hay un acuerdo semántico mínimo sobre los dos conceptos que aparecen en el título, en seguida se plantea la difícil cuestión del significado de "originario", entre "original" $\mathrm{i}$ "originante", así como la no menos difícil del doble aspecto en el significado de "fundamentación": dependencia ontológica ("Gründung") y justificación ("Begründung"), que recoge el doble significado del alemán "Grund" (fundamento-base-fondo, y razón). A decir verdad, no plantearse estas cuestiones es casi imposible para quien piense que el sentido de la fenomenología (de hecho, no sólo de la fenomenología sino que "mutatis mutandis" nos encontramos algo análogo en la mejor filosofía analítica) consiste en aunarlas sin sacrificar la una a la otra, y en integrar los dos aspectos semánticos de cada uno de los dos conceptos en cuestión sin sacrificar el uno al otro.

El acuerdo semántico mínimo al que acabo de apelar me sugiere la tímida conjetura de que tal vez se puede aceptar que el título serviría para caracterizar en general el programa de la fenomenología. Claro está que a lo mejor este consenso es también de mínimos y se debe tan sólo a que la conjunción " $y$ " bien poca cosa dice: ¿Habria que decir mejor: "experiencia originaria como fundamentación"? ¿O a la inversa? ¿O son términos equivalentes? ¿Cómo hay que entender el vínculo? Ya aquí el disenso ganaría terreno. Un buen pro- 
blema, que no se limita a esto: hay quien piensa justamente que hay que desvincular el concepto de fundamentación del concepto de experiencia originaria. Lo piensan los filósofos (por cierto, analíticos o continentales) de orientación pragmatista y que defienden una epistemología (y por tanto, una teoría de la justificación) coherentista e intradiscursiva, y no fundacionalista. Pero hay quien piensa la desvinculación en sentido contrario, en el sentido de una experiencia originaria como opuesta a la fundamentación: Si contemplamos la historia del movimiento fenomenológico, no sólo constatamos que la "Phänomenologengemeinschaft" no es la que Husserl había originariamente planeado (aquí asoma, por cierto, la diferencia entre original y originante), sino que en muchos casos acaba llevando a algo que reclamaría un título como: "experiencia originaria o fundamentación" (donde la conjunción "o" es la disyunción excluyente), o bien "experiencia originaria versus fundamentación", o incluso: "experiencia originaria como no o como des- fundamentación" (o "desfondamiento", si Uds. quieren tocar la resonante cuestión del nihilismo), como podemos caracterizar, se dice, la posición del Heidegger maduro.

En rigor, en la medida en que la comunidad fenomenológica prevista por Husserl no se llega a formar como comunidad científica, pero sólo porque se cuestiona el cumplimento por parte de Husserl, y no la intención, del " $A n$ fang", pongamos por caso, puede decirse que el sentido por él fundado se mantiene, y bajo el título que hemos propuesto; incluso cabe pensar que las críticas de otros, como quiera que las valoremos, responden al mismo principio o sentido fenomenológico y se dan la mano con las autocríticas de Husserl, incluso que tal vez las motivan de alguna manera en el modo en que se motivan mutuamente los miembros de una comunidad intelectual, por precaria que sea su cohesión interna.

Antes de seguir se impone aquí, sin embargo, una cierta precaución: externa o internamente motivada, la evolución de Husserl no mantiene invariables los contenidos de los conceptos de experiencia originaria y de fundamentación, ni el del vínculo entre ambas. Y la suposición en sentido contrario es en parte responsable de la imagen-cliché tan extendida sobre el fundador de la fenomenología. Pero sí se mantienen, si se me permite decirlo así, los conceptos formales correspondientes, en contra de otro tópico, por cierto a veces combinado con el anterior: el de la conversión del Husserl tardío a vaya Ud. a saber qué.

La pregunta, entonces, sería la siguiente: ¿En qué queda la fenomenología si se desvinculan los dos miembros de la conjunción? Más precisamente: ¿Queda la fenomenología si cae uno de ellos?

Veamos: En primer lugar, fundamentación sin experiencia originaria: Algunos intérpretes de indudable competencia ponen de relieve los elementos coherentistas, perspectivistas, pluralistas, relativistas de Husserl basándose, por ejemplo, en el concepto de horizonte. Sin negar que Husserl tiene en cuenta estos aspectos, yo sigo sin ver que se le pueda atribuir una posición 
antifundacionalista, y menos sobre la base del concepto de horizonte (al que me referiré brevemente en seguida). Si cae el fundacionalismo, si se quiere, para ser cautos, el concepto formal del mismo (siendo un poco menos cautos, el "principio de todos los principios"), entonces a mi parecer cae, no queda, la fenomenología.

Pero tal vez no ocurra lo mismo si lo que cae es el concepto de fundamentación. Según eso, sería posible una fenomenología desfundamentadora, y precisamente por radicalización del otro elemento, la experiencia originaria. Este sería el caso de Heidegger, para resumir lo irresumible, en su cuestionamiento de la "metafísica de la presencia" y su apelación a la diferencia ontológica como el juego de la ocultación en la desocultación donde la experiencia originaria seria el corresponder epocal del "Dasein" a este juego en diversas formas de existencia como "ek-sitencia": lenguaje, técnica, arte, política, etc.

Pero aquí me asaltan dos de las mayores dudas de que hablaba al principio: La primera es si esto no es al fin y al cabo un juego de fundamentación, si se toma el concepto justamente en sentido formal (dependencia, por ejemplo, recíproca o unilateral), sin restringirlo a la relación (causal, pongamos por caso, o de correlación, o de representación, se entienda ésta a su vez en términos causales o de otro modo) entre un ente y otro ("ontoteología").

La segunda duda es más grave y no afecta tanto al concepto de fundamentación como al mismo concepto de experiencia originaria. Estoy con los que piensan que, no sólo Heidegger en toda su trayectoria, sino otras figuras mayores del movimiento fenomenológico, como Sartre, Merleau Ponty o Levinas, han explorado el campo de los fenómenos en todos sus claroscuros y su dimensión trágica con una intensidad y una vocación que uno no encuentra tan fácilmente en Husserl. Alguien más sabio que yo me decía, concretamente hablando de Sartre, que el problema de Husserl era su resistencia a reconocer la negatividad insita en el mundo y en la condición humana. Bien: con todo, yo osaría replicar que, aun si en el campo fenoménico nos hacen frente la cara oscura, el elemento trágico, las ocultaciones, los límites, incluso el mal radical en el hombre y en su experiencia, todo ello ha de poder ser dado, y ciertamente como lo que es, como lo negativo vivo y no meramente privativo, por así decir. Ha de mostrarse a la mirada fenomenológica en la actitud correspondiente, la cual, en ella misma, sin embargo, no puede contener en sí negatividad, aunque se acceda a ella por la negación o desconexión de otras. Más aun: por ser esta desconexión un tránsito que pone a la mirada fenomenológica frente al campo de juego de toda positividad y toda negatividad, esta mirada no puede s positiva ni negativa en el sentido de aquello que es lo uno o lo otro en el campo fenoménico. O mejor: es "positiva" en el sentido que se corresponde con el mismo concepto formal de fenómeno, compatible justamente con el juego de positividad y negatividad en su materialización en fenómenos particulares. Y es esta mirada la que corresponde a la experiencia originaria como experiencia fenomenológica que, por no poder ser negativa, no puede ser des- 
fundamentadora: puede encontrar abismos o lagunas, o reconocer límites, pero ni los aporta ella misma al fenómeno ni los incorpora a sí misma desde el mismo (no los hereda) sino que, al encontrarlos, se le muestran en su lugar en el complejo campo fenoménico siempre "horizontal" al que pertenecen, con lo que los fundamenta en el único modo en que la fenomenología puede fundamentar: la aprehensión y la correspondiente descripción (si caben las palabras) o la simple mostración (si no caben) En suma, veo la negatividad en lo fenoménico, pero no veo que pueda haberla en lo fenomenológico. Y no puedo dejar de pensar que en este punto la $\varepsilon \pi \circ \chi \eta$ husserliana representa la ventaja de Husserl respecto de otros fenomenólogos, que consiste en reconocer que él hace lo que los otros, Sartre, Merleau Ponty, Heidegger hacen también sin tenerlo claro como filósofos fenomenológicos: la función del espectador desinteresado, sea cual sea la motivación y la vía que les ha conducido a esta función, de la cual está exenta la negatividad por lo mismo por lo que puede hallarla y situarla sin negarla (fundamentarla) en el campo que abarca su mirada.

O esto, o la filosofía es simple expresión de la vida. Pero si algo así es filosofía, a mi modesto entender, no es filosofía fenomenológica. Así que, a fin de cuentas, es posible que Heidegger caiga bajo nuestro título, aunque sus manifestaciones al respecto son más bien ambiguas. Y la exclusión del Heidegger tardío del territorio fenomenológico puede ser más bien debida a "disputas de escuela". Aunque a decir verdad no se trata - sería poco fenomenológico - de aferrarse a los términos, tampoco al término "fenomenología", como si fuera cuestión de patentes. También esto es un horizonte abierto.

Ahora bien, aun si el proyecto fenomenológico que recoge el título tiene un sentido, tal vez suceda que este sentido no tenga cumplimiento. La experiencia originaria sería, como tal, experiencia pura, y la fundamentación en ella fundamentación absoluta de lo que Husserl osa llamar nada menos que "una vida en la apodicticidad". Ello significaría, me parece, que idealmente la fenomenología debería fundamentar en la experiencia originaria, por ejemplo, TODAS nuestras creencias (en el sentido de más amplio de "beliefs", que incluiría, por cierto, también lo que Ortega llama específicamente "creencias" en oposición a "ideas") y la articulación y el orden entre las mismas, y remitir a dicha experiencia todos nuestros conceptos y el orden de los mismos.

Pero es dudoso que este proyecto racional ideal pueda traducirse en un programa razonable. De facto, es patente que nuestra experiencia está siempre saturada de creencias de partida, de lenguajes históricos, de conceptos transmitidos y heredados, de formaciones de sentido en los que ya siempre estamos, de perspectivas particulares, etc.

En este contexto, la fenomenología, bien que movida en el fondo de su corazón por el ideal de la experiencia originaria, puede promover (¡fundamentar!) un programa razonable basado en la aprehensión y la descripción de los fenómenos que se dan como sentidos en una experiencia que ya no es pura 
o originaria por estar ya de entrada previamente articulada y fácticamente contextualizada.

Dicho en otros términos: el ideal una fundamentación absoluta que sigue acaso valiendo como ideal racional pero que es un progama irrealizable, rinde (y me atrevería a decir, sólo él rinde, por ejemplo, dando a cada perspectiva sobre campos fenoménicos particulares conciencia de perspectiva y de particularidad, acompañada de conciencia de horizonte, horizonte que, si bien supone un centro y un "estilo"particulares, esto es, límite y pluralidad, apunta siempre al más allá de una "infinitud abierta" - en este sentido cabría elaborar acaso la diferencia entre "escenario", cerrado en sí mismo, y "horizonte", a la vez esencialmente limitado y esencialmente abierto, - rinde, decía, después de todo la fundamentación de un programa fenomenológico más razonable, menos radical pero más viable, con suficientes señas de identidad como para ser una alternativa consistente a otras formas en boga de considerar las cosas y la experiencia de las cosas. En suma, lo que se reivindica es el "método fenomenológico", que tan buen trabajo ha llevado a cabo ya en su venerable andadura en el siglo pasado.

Ahora bien, este método tiene como correlato lo que Heidegger llama, en el "Methodenparagraph" (7) de Sein und Zeit, el "concepto formal de fenómeno", sólo que en su materialización en el concepto que llama "vulgar". Ciertamente, Heidegger completa el análisis con el "concepto fenomenológico de fenómeno": "Lo que en los fenómenos entendidos en sentido vulgar se muestra ya previa y concomitantemente, aunque atemáticamente, ha de ser llevado a mostrarse temáticamente, y este mostrarse-así-en-sí-mismo son los fenómenos de la fenomenología". Este pasaje, así como la afirmación subsiguiente: "Esencialmente no hay nada detrás de los fenómenos", lo que quiere decir, detrás del fenómeno vulgar está el fenómeno fenomenológico pero no hay nada detrás de éste, permite entrever, creo, primero, que este fenómeno sería el correlato la experiencia originaria y, segundo, que este pasaje podría haber salido de la pluma de Husserl. Pero esto último se debe tan sólo al hecho de que esta caracterización lo es sólo de lo que podríamos considerar el concepto formal del fenómeno fenomenológico (e, implícita y correlativamente, de la correspondiente experiencia originaria). Por el contrario, las posiciones de Heidegger y de Husserl se distinguen como materializaciones opuestas del concepto formal del concepto fenomenológico de fenómeno.

Ahora bien, así como hay y debe haber materializaciones distintas del concepto vulgar, porque esto pertenece esencialmente al método fenomenológico y a sus rendimientos, es esencial que no las haya del fenómeno fenomenológico.

En mi opinión, no es absurdo pensar que hay una lectura posible de Husserl y de Heidegger como dos fenomenólogos que ponen la mirada fenomenológica en ámbitos fenoménicos distintos y nos proporcionan descripciones admirables de los mismos. Como, dicho sea de paso, esperaba Husserl de los 
que consideraba sus dos mejores discípulos: Oscar Becker, fenomenología de la matemática; Heidegger, fenomenología de la religión. Claro, porque pensaba que el fenómeno fenomenológico era cosa suya. Pero justamente esto es lo que le cuestiona Heidegger. En realidad, lo que pensaba cada uno del otro era que confundía el fenómeno fenomenológico con el fenómeno vulgar o, correlativamente, que ponía en el lugar de la experiencia originaria una experiencia modificada o derivada.

Acaso cabe pensar que, dadas las dificultades inherentes al esclarecimiento del fenómeno fenomenológico de que ya hemos hablado, lo que ocurre es que este esclarecimiento se implementa por la vía de la retroyección o repercusión del fenómeno vulgar en el fenomenológico. Pero esto equivaldría a negarles lo que tienen en común como filósofos, algo a lo cual yo no me encuentro dispuesto, porque no me puedo creer (por lo menos hasta ahora) que el litigio entre Husserl y Heidegger se resuelva en favor de Dilthey, pongamos por caso.

Más bien creo, todavía, que hay que elegir entre una vía y la otra, calibrando, sin duda del único modo posible, a saber, intentando poner la mirada en la cosa misma, lo que tienen en común y lo que separa a los dos filósofos; analizando por ejemplo el texto de la "Parte preparatoria" de Prolegomena zur Geschichte des Zeitbegriffs (Gesamtausgabe, vol. 20; traducción castellana: Madrid, Alianza, 2006)), donde Heidegger pretende llevar a cabo una "reflexión radical" en el modo de una "crítica inmanente" de la fenomenología de Ideas I después de reconocerse inequívocamente en la fenomenología y de haber hecho suyos - claro está que, como siempre, a su manera - lo que para él son los "descubrimientos fundamentales" de las Logische Untersuchungen. Es algo que no cabe hacer ahora, pero no puedo dejar de pensar que Husserl y Heidegger han afrontado con más vigor y seriedad el fenómeno fenomenológico de lo que lo han hecho los que se encuentran en las respectivas estelas, en general más víctimas que ellos de la retroyección del fenómeno vulgar.

En fin, concluiré con algo que hubiese sido un tema más sensato, acotado y adecuado para una charla como esta que aquél por el cual he tenido el atrevimiento de pedirles su tiempo y atención. Quizás por un acto de contrición no quería terminar sin decir algo del mismo.

Sea lo que sea de las posiciones de Husserl y de Heidegger, de las diferencias de personalidad, formación, intereses intelectuales y de otro tipo, de discrepancias y coincidencias, dejando de lado incluso si no son diferentes, no ya el contenido, sino incluso el mismo método fenomenológico, quisiera mostrar lo que podríamos llamar, a falta de una expresión mejor, el "espíritu fenomenológico" que comparten, y que comparten con todos, o casi todos, los miembros de la comunidad fenomenológica, por muy dispersa y deslavazada que ésta pueda ser:

El gran texto de Husserl "El origen de la geometría" (Husserliana VI, 365-386) se presta, como tantos otros de Husserl y de Heidegger, a servir de 
base para el análisis de coincidencias y diferencias. Pero aquí buscamos el espíritu común de la fenomenología. Tiene un nombre (entre otros posibles): "Bodenständigkeit", de difícil traducción: "arraigo" o "enraizamiento", que por lo demás pueden dar lugar a equívocos antifenomenológicos fatales. Heidegger mismo lo usa para caracterizar, refiriéndose a Husserl, la investigación fenomenológica: "bodenständig ausweisend forschen" (Proleg., \& 8). Esta "Bodenständigkeit es, naturalmente, también un concepto formal con materializaciones diferentes en uno y en otro. No tanto, empero, coma para no caracterizar un "espíritu" común; en lógica contraposición con aquello que combate, la "Bodenlosigkeit", precisamente el espíritu de la fenomenología.

Ello se traduce, pese a todas las diferencias en las respectivas concepciones del lenguaje, en una llamativa coincidencia, casi textual, sobre su sentido, justo en contextos bien distintos. En el texto de Husserl, respecto de la comprensión de la expresión lingüística como "reactivación" del sentido de la evidencia, encontramos: "Pero existen también posibilidades de un modo de actividad, de de un pensar en meras pasividades tomadas receptivamente, sin ninguna evidencia de la actividad originaria". Y añade poco después: "[...] la vida intuitiva originaria... cae ('verfällt') muy rápidamente i de manera creciente en la seducción del lenguaje". Y luego, hablando de las "formaciones ('Bildungen') asociativas": "Con la inevitable sedimentación de los productos espirituales en forma de adquisiciones persistentes del lenguaje que cualquier otro puede hacer suyas, son un peligro constante".

De lo que Husserl habla es, con todas las diferencias, de lo que, en el \& 35 de Sein und Zeit, Heidegger llama "Gerede" como "caída" ("Verfall”) del habla ("Rede") en la "existencia impropia". Así: "De acuerdo con la comprensibilidad mediana, que radica ya en el lenguaje hablado en su expresarse, el habla comunicada puede ser ampliamente comprendida sin que el que oye acceda a un ser originariamente comprensor e aquello de lo que se habla". Más adelante: "Y dado que el hablar ha perdido, o no ha ganado nunca, la relación de ser primaria con aquello de lo que habla, no se comunica en el modo de la apropiación originaria con el ente en cuestión, sino por la vía del seguir hablando y el repetir", con lo cual "la 'Bodenständigkeit' que ya faltaba al principio aumenta hasta llegar a la plena 'Bodenlosigkeit", y así "se constituye el Gerede".

Naturalmente, el análisis comparativo podría y debería aportar más elementos, textuales y de todo tipo. Pero también podría alguien objetar, por ejemplo, la obvia diferencia de vocabularios, contextos, propósitos, etc. Tendría toda la razón. Pero quizás ello indique, después de todo, que algo hay independiente de lenguajes, contextos, etc., a saber, el espíritu de la fenomenología. 
